\title{
Towards the Prediction of Renewable Energy Unbalance in Smart Grids
}

\author{
Ruggero Donida Labati, Angelo Genovese, Vincenzo Piuri, Fabio Scotti \\ Department of Computer Science, Università degli Studi di Milano, Italy. \\ \{ruggero.donida, angelo.genovese, vincenzo.piuri,fabio.scotti\}@unimi.it
}

\begin{abstract}
The production of renewable energy is increasing worldwide. To integrate renewable sources in electrical smart grids able to adapt to changes in power usage in heterogeneous local zones, it is necessary to accurately predict the power production that can be achieved from renewable energy sources. By using such predictions, it is possible to plan the power production from non-renewable energy plants to properly allocate the produced power and compensate possible unbalances. In particular, it is important to predict the unbalance between the power produced and the actual power intake at a local level (zones). In this paper, we propose a novel method for predicting the sign of the unbalance between the power produced by renewable sources and the power intake at the local level, considering zones composed of multiple power plants and with heterogeneous characteristics. The method uses a set of historical features and is based on Computational Intelligence techniques able to learn the relationship between historical data and the power unbalance in heterogeneous geographical regions. As a case study, we evaluated the proposed method using data collected by a player in the energy market over a period of seven months. In this preliminary study, we evaluated different configurations of the proposed method, achieving results considered as satisfactory by a player in the energy market.
\end{abstract}

\section{INTRODUCTION}

Green technologies and power production based on renewable sources have been constantly gaining attention in recent years [1], especially to develop electrical smart grids with optimized power production and distribution [2]. To increase the adoption of electrical power produced using renewable energy, the research community is studying innovative methods to predict the electrical load [3], estimate the energy cost [4], increase the energy efficiency of buildings [5], and optimize the energy consumption of production processes [6], [7].

The most important sources of renewable energy are represented by the wind and solar activity. Recent market analyses indicate that the wind power accounts for 5\% of the global electricity consumption and is growing at $16.1 \%$ per year [8], [9], while predicting that in the year 2050 solar energy will account for $27 \%$ of the global consumption [10].

With the increasing adoption of renewable energy sources to generate electrical power, it is becoming more and more necessary to accurately predict the power produced by renewable energy plants to plan the production of non-renewable energy [11]. In fact, while storing the produced electrical power could represent a solution to the unbalance problem, such storage is usually not efficient nor environmentally sustainable [12].

Predicting the unbalance between the power produced using renewable sources and the power intake is also important

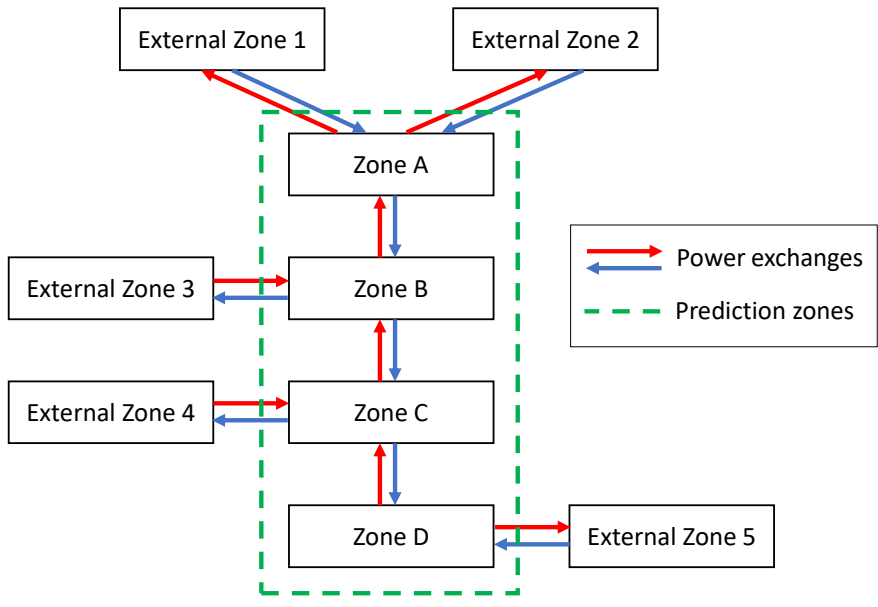

Fig. 1. Example of a smart grid composed by four local zones (A-D) and five external zones (1-5) that can receive or supply power in the case of power unbalances.

for players in the energy market, since the market applies penalties when the produced power differs from the actual intake [13]. For this reasons, the companies need accurate power predictions and decision support tools [5], [14], [15]. It is especially important to predict at a local level (zone) when the sign of the unbalance between the produced power and the actual power intake is positive (more power produced than necessary) or negative (less power produced than necessary). Fig. 1 shows an example of a smart grid composed by four local zones for which the power unbalance needs to be predicted. The local zones include different numbers of power plants with heterogeneous production characteristics.

In this paper, we propose a preliminary study on a novel method to predict the sign of the power unbalance in local zones of smart grids integrating plants for the production of renewable and non-renewable energy. Our method uses a set of historical features to output whether the unbalance in each zone will be positive or negative. We use Computational Intelligence $(\mathrm{CI})$ techniques to learn the relationship between historical data and the power unbalance in different conditions of the territory and periods of the year.

To the best of our knowledge, the proposed method is the first one using CI techniques to predict the sign of the power unbalance of renewable energy in smart grids.

We evaluated the proposed method on a case study consisting of data collected in local zones by a player in the 
energy market for the duration of seven months. We considered the day-after market, in which it is necessary to perform the predictions 24 hours ahead [13], but the method is general and can be applied to different geographical areas, periods, and markets. We tested different configurations of the method and different training strategies, achieving satisfactory results.

The paper is structured as follows. Section II presents a literature review on the prediction of the power unbalance using renewable energies. Section III describes the proposed method for predicting the sign of the power unbalance. Section IV discusses the experimental results obtained by evaluating the method on the considered case study. Finally, Section V concludes this work.

\section{LITERATURE REVIEW}

In the field of environmental monitoring, CI techniques often achieve state-of-the-art results thanks to their ability to learn by examples the complex relations between geographical and weather information and the phenomenon of interest, as well as their capability to cope with noisy or incomplete data [16], [17], [18], [19], [20]. Applications of CI for environmental monitoring include the prediction of adverse conditions [21], time series forecasting [22], [23], and the prediction of power produced from renewable energy sources [8], [24], [25], [26].

Most studies in the literature focus on predicting the power production from wind and solar activity using different CI techniques, such as support vector machines [26], [27], artificial neural networks [28], [29], fuzzy rules [30], [31], and deep learning [32], [33]. In the field of wind and solar energy prediction, $\mathrm{CI}$ exhibited superior performance over autoregressive models when large numbers of training samples are available [34]. However, the accuracy of prediction methods is affected by different aspects, such as the training procedure, spatial and temporal resolution of historical data, and the time in advance for which the prediction is needed [35].

To the best of our knowledge, the work in [12] is the only method in the literature that predicts the sign of the power unbalance. However, it considers only statistical autoregressive models.

\section{Proposed Method}

We propose a method for the day-ahead prediction of the sign of the power unbalance in local zones of smart grids integrating renewable and non-renewable energy plants. The method uses CI techniques based on Feed-Forward Neural Networks (FFNNs) to perform the hourly predictions with a time horizon of one day.

We consider $t_{i}$, with $0<i<N$, as the times for which historical data is present. For the case study considered, our method uses data available every hour and performs the prediction for the next day (i.e., $t_{j}=t_{i}+24$ ).

To perform the prediction for each instant of time $t_{j}$ and each local zone, we use all the available features for every local zone at time $t_{i}$, obtaining the feature set $F\left(t_{i}\right)$. Input data include the date, historical time series of power intake, power
TABLE I

SUMMARY OF THE FEATURE SET $F\left(t_{i}\right)$ USED FOR THE PREDICTION OF THE SIGN OF THE POWER UNBALANCE, CONTAINING HISTORICAL DATA AVAILABLE AT EACH TIME INSTANT $t_{i}$

\begin{tabular}{|c|c|}
\hline N. & Description \\
\hline $1-2$ & Date (day (1 to 31$)$, month (1 to 12$)$ ) \\
\hline 3 & Day of the week (1 to 7 ) \\
\hline 4 & Hour (0 to 23$)$ \\
\hline 5 & $\begin{array}{l}\text { Festive ( } 1=\text { working day; } 2=\text { pre-holiday; } 3= \\
\text { holiday) }\end{array}$ \\
\hline 6 & Modality (boolean) \\
\hline 7 & Hourly price range (1 to 3 ) \\
\hline $8-11$ & Forecasted power load for Zones A to D \\
\hline $12-15$ & Forecasted wind power produced for Zones A to D \\
\hline $16-19$ & Forecasted solar power produced for Zones A to D \\
\hline $20-21$ & $\begin{array}{l}\text { Foreign power import limits (applicable only to } \\
\text { Zones A and D for geographical reasons) }\end{array}$ \\
\hline $23-37$ & Local power import limits between local sub-regions \\
\hline $38-41$ & $\begin{array}{l}\text { Total energy sold } 2 \text { days before }\left(t_{i}-48\right) \text { for Zones } \\
\text { A to D }\end{array}$ \\
\hline $42-45$ & $\begin{array}{l}\text { Total energy bought } 2 \text { days before }\left(t_{i}-48\right) \text { for Zones } \\
\text { A to D }\end{array}$ \\
\hline $46-49$ & $\begin{array}{l}\text { Total energy sold } 7 \text { days before }\left(t_{i}-168\right) \text { for Zones } \\
\text { A to D }\end{array}$ \\
\hline $50-53$ & $\begin{array}{l}\text { Total energy bought } 7 \text { days before }\left(t_{i}-168\right) \text { for } \\
\text { Zones A to D }\end{array}$ \\
\hline $54-57$ & $\begin{array}{l}\text { Renewable energy produced } 1 \text { day before }\left(t_{i}-24\right) \\
\text { for Zones A to D }\end{array}$ \\
\hline $58-61$ & $\begin{array}{l}\text { Non-renewable energy produced } 1 \text { day before }\left(t_{i}-\right. \\
24) \text { for Zones A to D }\end{array}$ \\
\hline $62-65$ & $\begin{array}{l}\text { Renewable energy produced } 7 \text { days before }\left(t_{i}-168\right) \\
\text { for Zones A to D }\end{array}$ \\
\hline $66-69$ & $\begin{array}{l}\text { Non-renewable energy produced } 7 \text { days before }\left(t_{i}-\right. \\
168) \text { for Zones A to D }\end{array}$ \\
\hline $70-73$ & $\begin{array}{l}\text { Unavailabilities for Zones A to D (e.g., due to } \\
\text { malfunction or maintenance) }\end{array}$ \\
\hline 74-77 & Forecasted temperature (in ${ }^{\circ} \mathrm{C}$ ) \\
\hline
\end{tabular}

produced using wind activity, power obtained using solar photovoltaic cells, market information for the previous days, and the limits of power exchanges between local zones. We experimentally observed that using all the available features for every local zone improves the prediction accuracy with respect of using data related only to a single local zone, probably because FFNNs can learn more information on energy exchanges between the regions (see Fig. 1). Table I summarizes the feature set $F\left(t_{i}\right)$.

We apply a CI-based method, trained using the procedure described in Section IV, on the feature set $F\left(t_{i}\right)$ to predict the sign of the power unbalance $\hat{s}$ at time $t_{j}=t_{i}+24$, as follows:

$$
\hat{s}\left(t_{j}\right)=\operatorname{PRED}\left(F\left(t_{i}\right)\right),
$$

where PRED is the trained CI-based predictor. Specifically, PRED is a binary classifier with output defined as follows:

$$
\operatorname{PRED}\left(F\left(t_{i}\right)\right)= \begin{cases}+1 & \text { if the energy unbalance } \geq 0 \\ -1 & \text { otherwise. }\end{cases}
$$

In this preliminary study, PRED is a FFNN. The network is composed of a single hidden layer consisting of tan-sigmoidal nodes and an output layer consisting of a single linear node. 


\section{EXPERIMENTAL RESULTS}

In this section, we introduce the proposed case study, we describe the experimental protocol, we present the figures of merit used to evaluate the performance of our method, and we evaluate the accuracy of our method for the considered case study.

\section{A. Case Study}

As a case study, we considered the data collected by a player in the energy market during a time span of 7 months, ranging from September 1, 2012, to March 31, 2013. We considered four local zones in a scenario in which the possible energy exchanges are defined by the structure of the electrical grid, summarized by the schema shown in Fig. 1. The total number of samples is $N=5088$, corresponding to the predictions performed every hour for the considered time span.

\section{B. Experimental Protocol}

To evaluate the performance of prediction methods, we used a k-fold cross validation strategy without performing any random permutation of the samples ( $\mathrm{kF}-\mathrm{NO}-\mathrm{RP})$. This strategy divides the dataset into $k$ partitions of samples contiguous in time. kF-NO-RP iteratively uses $k-1$ partitions to train a classifier and the remaining partition to evaluate the prediction accuracy. As shown in the literature [8], this validation strategy is particularly suitable to evaluate the performance of prediction methods. In fact, prediction methods can achieve too optimistic performance if evaluated using traditional k-fold cross validation strategies performing random permutations of the samples (kF-RP) since they do not consider the temporal evolution or possible dependencies in the data [36]. To simulate real application conditions, it would be necessary to divide the dataset in a training set composed of samples acquired before a defined instant of time and a test set composed of the remaining samples. However, such procedure does not consider all data available for evaluation. Differently, kF-NORP achieves results similar to real application conditions while using all the available data [36]. In this paper, we used $k=10$.

\section{Figures of Merit}

We evaluated the performance of our method using figures of merit typically adopted for classification problems. Considering an error vector $E$, consisting of a binary vector representing the inequalities between the predicted and target classes, we evaluated the total classification error mean $(E)$, the standard deviation $\operatorname{std}(E)$, and the confusion matrix [37], analyzing the percentages of True Positives (TP), True Negatives (TN), False Positives (TP), and False Negatives (FN).

\section{Accuracy Evaluation}

We evaluated the performance of our proposed predictor based on FFNN by varying the number of nodes $n_{h}$ in the hidden layer in the range $n_{h} \in\{1, \ldots, 50\}$. The selected learning technique is based on the Levenberg-Marquardt training algorithm [38].
We compared the performance of our method with that of other well-known techniques in the literature. The first technique is based on the persistence of the output in previous instants of time and is commonly used as a reference for comparing novel models of prediction. The main idea behind this method is to exploit the repetitiveness of the phenomenon at known intervals of time. It is defined as: $\hat{s}\left(t_{j}\right)=s\left(t_{j-\Delta}\right)$, where $s\left(t_{j-\Delta}\right)$ is the sign of the production unbalance measured at time $t_{j-\Delta}$ and $\Delta$ is a constant of time expressed in hours. We also compared the performance of our method with that of $\mathrm{kNN}$ classifiers considering numbers of nearest neighbors $k_{n n}$ in the range $k_{n n} \in\{1, \ldots, 11\}$.

Table II summarizes the results achieved by the compared predictors validated using $\mathrm{kF}-\mathrm{NO}-\mathrm{RP}$ with $k=10$, reporting the results of the best configurations of $\mathrm{kNN}$ and FFNN classifiers. The table shows that FFNN classifiers achieved the best performance for all the 4 zones. Differently, methods based on the persistence and on kNNs achieved unsatisfactory results, proving the complexity of the classification problem. A player in the energy market considered the results achieved using FFNNs as positive and a starting point for designing a decision support tool.

Table III reports the confusion matrices of the best configurations of the neural predictors for every considered local zone, showing that the error is balanced in terms of FP and FN. Furthermore, this table shows that FFNN predictors can be effectively applied in heterogeneous conditions since the numbers of TP and TN present strong differences among the considered zones.

We also evaluated a feature reduction strategy based on the principal component analysis and forward feature selection methods [39], without obtaining performance improvements.

\section{CONCLUSION AND FUTURE WORK}

This paper presented a preliminary study on a novel method for the day-ahead prediction of the sign of the power unbalance in local zones of smart grids integrating power produced using renewable and non-renewable energies.

Our proposed method is general and applicable to different geographic areas, markets, and different prediction intervals. The method processes historical time series and predicts the sign of the power unbalance in local zones of the grid, to learn different operational and environmental conditions and cope with noisy data.

We evaluated the proposed method on data collected in local zones by a player in the energy market for a period of seven months, using different predictors and CI techniques. The results show the validity of the proposed method in predicting the sign of the power unbalances when dealing with the variability of power produced using non-renewable energies.

To further improve the achieved accuracy, future studies should consider bigger training datasets spanning multiple years, which were not available during the activities described in the paper. Future works should also consider other CI 
TABLE II

ACCURACY OF DIFFERENT CLASSIFIERS VALIDATED USING KF-NO-RP WITH K $=10$

\begin{tabular}{|c|c|c|c|c|c|c|c|c|c|c|c|c|}
\hline $\begin{array}{l}\text { Predictor } \\
\text { PRED }\end{array}$ & Parameters & $\begin{array}{l}\text { Zone A } \\
\text { mean }(E)\end{array}$ & $\operatorname{std}(E)$ & Parameters & $\begin{array}{l}\text { Zone B } \\
\text { mean }(E)\end{array}$ & $\operatorname{std}(E)$ & Parameters & $\begin{array}{l}\text { Zone } \mathbf{C} \\
\operatorname{mean}(E)\end{array}$ & $\operatorname{std}(E)$ & Parameters & $\begin{array}{l}\text { Zone D } \\
\text { mean }(E)\end{array}$ & $\operatorname{std}(E)$ \\
\hline Persistence & $\Delta=48$ & 0.574 & 0.495 & $\Delta=48$ & 0.653 & 0.476 & $\Delta=48$ & 0.744 & 0.437 & $\Delta=48$ & 0.610 & 0.488 \\
\hline Persistence & $\Delta=168$ & 0.592 & 0.492 & $\Delta=168$ & 0.643 & 0.479 & $\Delta=168$ & 0.712 & 0.453 & $\Delta=168$ & 0.612 & 0.487 \\
\hline kNN & $\vec{k}_{n n}=1$ & 0.413 & 0.492 & $\vec{k}_{n n}=1$ & 0.360 & 0.480 & $\vec{k}_{n n}=1$ & 0.365 & 0.481 & $\vec{k}_{n n}=1$ & 0.376 & 0.484 \\
\hline $\mathrm{kNN}$ & $k_{n n}=11$ & 0.354 & 0.478 & $k_{n n}=11$ & 0.270 & 0.444 & $k_{n n}=9$ & 0.336 & 0.472 & $k_{n n}=11$ & 0.329 & 0.470 \\
\hline FFNN & $\mathbf{n}_{\mathrm{h}}=35$ & 0.131 & 0.337 & $\mathbf{n}_{\mathbf{h}}=\mathbf{3 0}$ & 0.100 & 0.300 & $\mathbf{n}_{\mathbf{h}}=\mathbf{3 0}$ & 0.072 & 0.259 & $n_{h}=40$ & 0.111 & 0.315 \\
\hline
\end{tabular}

Notes: mean $(E)=$ total classification error, corresponding to the mean of the error vector $E ; \operatorname{std}(E)=$ standard deviation of the error vector $E ; \Delta=$ number of hours before the prediction instant $t_{j} ; k_{n n}=$ number of nearest neighbors considered by a kNN; FFNN = feedforward neural network; $n_{h}$ number of nodes in the hidden layer of a FFNN.

TABLE III

CONFUSION MATRIX OF THE PROPOSED METHOD IN ITS BEST CONFIGURATION

\begin{tabular}{lcccc}
\hline & TP & FP & FN & TN \\
\hline Zone A & 0.273 & 0.080 & 0.051 & 0.597 \\
Zone B & 0.727 & 0.074 & 0.027 & 0.173 \\
Zone C & 0.634 & 0.032 & 0.040 & 0.294 \\
Zone D & 0.221 & 0.033 & 0.078 & 0.668 \\
\hline
\end{tabular}

Notes: $\mathrm{TP}=$ True positives; FP $=$ False Positives; FN = False Negatives; TN $=$ True Negatives.

approaches based on convolutional neural networks and deep learning techniques.

\section{REFERENCES}

[1] F. Manzano-Agugliaro, A. Alcayde, F. G. Montoya, A. Zapata-Sierra, and C. Gil, "Scientific production of renewable energies worldwide: An overview," Renewable and Sustainable Energy Reviews, vol. 18, pp. 134-143, 2013.

[2] M. G. Simões, R. Roche, E. Kyriakides, S. Suryanarayanan, B. Blunier, K. D. McBee, P. H. Nguyen, P. F. Ribeiro, and A. Miraoui, "A comparison of smart grid technologies and progresses in Europe and the U.S." IEEE Trans. on Industry Applications, vol. 48, no. 4, pp. 1154-1162, July 2012.

[3] M. M. B. R. Vellasco, M. A. C. Pacheco, L. S. R. Neto, and F. J. de Souza, "Electric load forecasting: evaluating the novel hierarchical neuro-fuzzy BSP model," Int. Journal of Electrical Power \& Energy Systems, vol. 26, no. 2, pp. 131-142, 2004.

[4] Z. Y. Xu, H. N. Qu, W. H. Shao, and W. S. Xu, "Virtual power plantbased pricing control for wind/thermal cooperated generation in China," IEEE Trans. on Systems, Man, and Cybernetics: Systems, vol. 46, no. 5, pp. 706-712, May 2016.

[5] R. Carli, M. Dotoli, R. Pellegrino, and L. Ranieri, "A decision making technique to optimize a buildings' stock energy efficiency," IEEE Trans. on Systems, Man, and Cybernetics: Systems, vol. 47, no. 5, pp. 794-807, May 2017.

[6] Z. Geng, J. Chen, and Y. Han, "Energy efficiency prediction based on PCA-FRBF model: A case study of ethylene industries," IEEE Trans. on Systems, Man, and Cybernetics: Systems, vol. 47, no. 8, pp. 1763-1773, August 2017.

[7] C. M. Cheng, S. L. Tsao, and P. Y. Lin, "SEEDS: A solar-based energyefficient distributed server farm," IEEE Trans. on Systems, Man, and Cybernetics: Systems, vol. 45, no. 1, pp. 143-156, January 2015.

[8] R. Donida Labati, A. Genovese, V. Piuri, F. Scotti, and G. Sforza, "A decision support system for wind power production," IEEE Trans. on Systems, Man, and Cybernetics: Systems, 2018.

[9] World Wind Energy Association (WWEA), "WWEA half-year report," 2016.

[10] International Energy Agency (IEA), “Technology roadmap: Solar photovoltaic energy," 2014.
[11] X. K. Gu, G. F. Fan, X. R. Wang, H. X. Zhao, and H. Z. Dai, "Summarization of wind power prediction technology," Power System Technology, vol. 31, no. 2, pp. 335-338, 2007.

[12] L. Di Persio, A. Cecchin, and F. Cordoni, "Novel approaches to the energy load unbalance forecasting in the Italian electricity market," Journal of Mathematics in Industry, vol. 7, no. 1, p. 5, February 2017.

[13] A. Giannitrapani, S. Paoletti, A. Vicino, and D. Zarrilli, "Bidding wind energy exploiting wind speed forecasts," IEEE Trans. on Power Systems, vol. 31, no. 4, pp. 2647-2656, 2016.

[14] A. F. Taha and J. H. Panchal, "Decision-making in energy systems with multiple technologies and uncertain preferences," IEEE Trans. on Systems, Man, and Cybernetics: Systems, vol. 44, no. 7, pp. 894-907, July 2014.

[15] A. Rikalovic, I. Cosic, R. Donida Labati, and V. Piuri, "Intelligent decision support system for industrial site classification: A GIS-based hierarchical neuro-fuzzy approach," IEEE Systems Journal, 2017.

[16] R. Donida Labati, A. Genovese, E. Muñoz, V. Piuri, F. Scotti, and G. Sforza, "Computational intelligence for industrial and environmental applications," in Proc. of the $8^{\text {th }}$ IEEE Int. Conf. on Intelligent Systems (IS), 2016, pp. 8-14.

[17] E. M. Petriu, G. G. Patry, T. E. Whalen, A. Al-Dhaher, and V. Z. Groza, "Intelligent robotic sensor agents for environment monitoring," in Proc. of the IEEE Int. Symp. on Virtual and Intelligent Measurement Systems (VIMS), 2002, pp. 14-19.

[18] R. Donida Labati, A. Genovese, V. Piuri, and F. Scotti, "Wildfire smoke detection using computational intelligence techniques enhanced with synthetic smoke plume generation," IEEE Trans. on Systems, Man, and Cybernetics: Systems, vol. 43, no. 4, pp. 1003-1012, July 2013.

[19] R. Donida Labati, A. Genovese, E. Muñoz, V. Piuri, and F. Scotti, “Applications of computational intelligence in industrial and environmental scenarios," in Learning Systems: From Theory to Practice, V. Sgurev, V. Piuri, and V. Jotsov, Eds. Cham: Springer International Publishing, 2018, pp. 29-46.

[20] B. Alsahwa, F. Maussang, R. Garello, and A. Chevallier, "Marine life airborne observation using HOG and SVM classifier," in Proc. of the OCEANS 2016 MTS/IEEE Monterey, September 2016, pp. 1-5.

[21] J. N. K. Liu, K. M. Kwong, and P. W. Chan, "Chaotic oscillatory-based neural network for wind shear and turbulence forecast with LiDAR data," IEEE Trans. on Systems, Man, and Cybernetics, Part C (Applications and Reviews), vol. 42, no. 6, pp. 1412-1423, November 2012.

[22] L. J. Herrera, H. Pomares, I. Rojas, A. Guillén, A. Prieto, and O. Valenzuela, "Recursive prediction for long term time series forecasting using advanced models," Neurocomputing, vol. 70, no. 1618, pp. 2870-2880, 2007.

[23] H. Dhahri and A. M. Alimi, "The modified differential evolution and the RBF (MDE-RBF) neural network for time series prediction," in Proc. of the IEEE Int. Joint Conf. on Neural Network (IJCNN), 2006, pp. 2938-2943.

[24] Z. Vale, G. K. Venayagamoorthy, J. Ferreira, and H. Morais, "Computational intelligence applications for future power systems," in Computational Intelligence for Engineering Systems: Emergent Applications, A. Madureira, J. Ferreira, and Z. Vale, Eds. Dordrecht: Springer Netherlands, 2011, pp. 176-193.

[25] M. Lazzaroni, S. Ferrari, V. Piuri, A. Salman, L. Cristaldi, and M. Faifer, "Models for solar radiation prediction based on different measurement sites," Measurement, vol. 63, pp. 346-363, 2015. 
[26] S. Ferrari, M. Lazzaroni, V. Piuri, A. Salman, L. Cristaldi, and M. Faifer, "Computational intelligence models for solar radiation prediction," in Proc. of the 2013 IEEE Int. Instrumentation and Measurement Technology Conf. (I2MTC), May 2013, pp. 757-762.

[27] Y. Zhang, P. Wang, C. Zhang, and S. Lei, "Wind energy prediction with LS-SVM based on Lorenz perturbation," The Journal of Engineering, vol. 2017, no. 13, pp. 1724-1727, 2017.

[28] R. Ata, "Artificial neural networks applications in wind energy systems: a review," Renewable and Sustainable Energy Reviews, vol. 49, pp. 534 $562,2015$.

[29] Z. Wang, I. Koprinska, and M. Rana, "Solar power prediction using weather type pair patterns," in Proc. of the 2017 Int. Joint Conference on Neural Networks (IJCNN), May 2017, pp. 4259-4266.

[30] H. Liu, H. qi Tian, and Y.-F. Li, "Comparison of new hybrid FEEMDMLP, FEEMD-ANFIS, Wavelet Packet-MLP and Wavelet PacketANFIS for wind speed predictions," Energy Conversion and Management, vol. 89, pp. 1-11, 2015.

[31] S. Jafarzadeh, M. S. Fadali, and M. Etezadi-Amoli, "Fuzzy type-1 and type-2 TSK modeling with application to solar power prediction," in Proc. of the 2012 IEEE Power and Energy Society General Meeting (PES), July 2012, pp. 1-6.

[32] A. S. Qureshi, A. Khan, A. Zameer, and A. Usman, "Wind power prediction using deep neural network based meta regression and transfer learning," Applied Soft Computing, vol. 58, pp. 742-755, 2017.

[33] A. Alzahrani, P. Shamsi, C. Dagli, and M. Ferdowsi, "Solar irradiance forecasting using Deep Neural Networks," Procedia Computer Science, vol. 114, pp. 304-313, 2017.

[34] S. S. Soman, H. Zareipour, O. Malik, and P. Mandal, "A review of wind power and wind speed forecasting methods with different time horizons," in Proc. of the North American Power Symp. (NAPS), September 2010 pp. $1-8$.

[35] J. Wang, Y. Song, F. Liu, and R. Hou, "Analysis and application of forecasting models in wind power integration: A review of multistep-ahead wind speed forecasting models," Renewable and Sustainable Energy Reviews, vol. 60, pp. 960-981, 2016.

[36] C. Bergmeir and J. M. Benítez, "On the use of cross-validation for time series predictor evaluation," Information Sciences, vol. 191, pp. 192$213,2012$.

[37] C. M. Bishop, Pattern recognition and machine learning, 5th Edition, ser. Information science and statistics. Springer, 2007.

[38] M. T. Hagan and M. B. Menhaj, "Training feedforward networks with the Marquardt algorithm," IEEE Trans. on Neural Networks, vol. 5, no. 6, pp. 989-993, November 1994.

[39] A. K. Jain, R. P. W. Duin, and J. Mao, "Statistical pattern recognition: a review," IEEE Trans. on Pattern Analysis and Machine Intelligence, vol. 22, no. 1, pp. 4-37, January 2000. 